\title{
An improved lure for trapping the bark beetle Dendroctonus armandi (Coleoptera: Scolytinae)
}

\author{
SHOU-An XIE and SHu-JiE LV \\ College of Forestry, Northwest A \& F University, Taicheng Rd 3, Yangling, Shaanxi 712100, P.R. China; \\ e-mails: shouanxie@126.com; shujielv@tom.com
}

Key words. Coleoptera, Scolytidae, Dendroctonus armandi, semiochemicals, GC-MS and GC-FID, analyses, trap, Pinus armandi

\begin{abstract}
The pine bark beetle, Dendroctonus armandi, is a native pest restricted to forests in the Qinling Mountains in China. There was an outbreak of this species there that affected over 0.36 million hectares of pine forest. We hypothesized that there are differences between the numbers of beetles captured by traps baited with various combinations of candidate semiochemicals extracted from the hindguts of $D$. armandi. In order to determine whether a better operational lure could be developed for $D$. armandi, we analyzed the volatiles in extracts of the hindgut of $D$. armandi and tested various combinations of candidate semiochemicals. The GC-MS and GC-FID analyses of volatiles in the extracts of the hindguts of $D$. armandi collected at different stages of the attack revealed that they are mainly $\alpha$-pinene, $\beta$-caryophyllene and (+)-3-carene with minor amounts of myrcene, limonene, verbenol and verbenone. We tested various combinations of these candidate semiochemicals in order to determine an optimal blend. Our results suggest that the addition of $\beta$-caryophyllene to either $\alpha$-pinene, or blends of $\alpha$-pinene and other candidate semiochemicals, significantly enhanced the attractiveness of the lures for $D$. armandi. Field trapping experiments indicated that the blends that included $\beta$-caryophyllene, myrcene and other candidate semiochemicals resulted in significantly higher trap catches (161-243\% higher) than $\alpha$-pinene alone. Therefore, a simple lure consisting of $\alpha$-pinene and $\beta$-caryophyllene would be an optimal blend for $D$. armandi. We conclude that this blend of semiochemicals may provide a better method of reducing the numbers of $D$. armandi in forest ecosystem.
\end{abstract}

\section{INTRODUCTION}

The pine bark beetle Dendroctonus armandi Tsai \& Li, which occurs throughout the Qinling Mountains, is one of the most important pests of mature Pinus armandii Franch in China (Wang et al., 2011). The life histories of Dendroctonus pine beetles can be characterized in terms of a sequence of behavioural components that culminate in the propagation of the species. The sequence begins with the emergence of adults from their host trees. They fly from the tree where they developed to a new host tree, where they bore through the bark and start constructing galleries in the phloem. As these beetles attack a tree, they also release certain semiochemicals that attract more beetles. As a result of this aggregative behaviour pine trees are successfully attacked, mating takes place, egg galleries are constructed, eggs are deposited, broods develop and adult beetles emerge to attack other trees. Like most bark beetles, D. armandi develops from the juvenile to the adult stage under the bark. The female beetle initiates the attack and uses chemical signaling to attract both males and females. $D$. armandi produces two generations per year throughout its distribution.

$D$. armandi may cause serious economic damage to pine forests throughout the beetle's distribution. For example, this pine bark beetle has killed $3 \times 10^{8} \mathrm{~m}^{3}$ of Chinese white pine in China since the 1970s. Because Pinus armandii is the preferred host of $D$. armandi, it may pose a significant threat to the Qinling Mountain forests. Considerable effort was expended in controlling the spread of D. armandi in these forests from 1998 to 2008. Management measures commonly include removing wind throws and sanitary logging of infested trees at an early stage of infestation. However, as an important management measure, semiochemical-based trapping to reduce the numbers of beetles has not been used.

Bark beetles commonly utilize specialized and complex semiochemical messages to locate and colonize trees suitable for breeding (Wood, 1982; Byers, 1999; Huber et al., 1999; Zhang et al., 1999a, b; 2000). Therefore, barriers of traps emitting volatiles might be one way of protecting pine stands, possibly by using such traps to protect selected stands by significantly lowering the primary beetle attack rate (Faccoli \& Stergulc, 2008; Stephen, 2001; Blazenec \& Jakus, 2009). Due to the essential role that these semiochemicals play in the beetles' ability to kill trees, substantial effort has been invested in developing semiochemical-based management techniques for controlling the following species: Dendroctonus frontalis, Dendroctonus brevicomis, Dendroctonus ponderosae and Dendroctonus valens (Hughes, 1973; Bertram \& Paine, 1994a, b; Yin, 2000; Li et al., 2001; Miao et al., 2001; Pureswaran \& Borden 2004; Sullivan, 2005; Zhang \& Sun, 2006; Erbilgin et al., 2007; Fettig et al., 2008; Pureswaran et al., 2008; Zhang et al., 2008, 2009a, b). However, previous studies have shown that $D$. armandi exploits olfactory cues emitted by $P$. armandii and other non-host species, and use them to locate new host trees (Chen et al., 2006; Wang et al., 2011). Bark beetles belonging to the genus Dendroctonus utilize not only some host odours, such as 3-carene, to locate susceptible hosts (Erbilgin et al., 2007) but also produce and release their own volatiles. Earlier studies of volatile production 
by $D$. valens, collected from naturally infested pine stumps, used paired adults and ovipositing females of uncertain age (Zhang \& Sun, 2006). However, previous studies indicate that both feeding and pairing influences the quantity and composition of the semiochemicals produced by bark beetles (Zhang et al., 2000a, b; Pureswaran $\&$ Borden, 2004). For this reason, it is likely we have not identified all the volatiles produced by the genus Dendroctonus. In contrast to the previous focus on screening mixtures of semiochemicals by evaluating flight responses, our objectives were to (1) identify the semiochemicals utilized by $D$. armandi, (2) determine the semiochemicals used in the different phases of the attack, (3) test the biological activity of the key male-specific compounds as flight attractants in the Qinling Mountain, (4) determine whether an improved operational lure could be developed for $D$. armandi, incorporating candidate semiochemicals in addition to $\alpha$-pinene. For commercial application, the lure must be significantly more attractive than $\alpha$-pinene alone and give reliable and consistent results.

\section{MATERIAL AND METHODS}

\section{Sample collection and preparation}

Live adults $D$. armandi in different phases of the subcortical attack (phase 1: unpaired female in nuptial chamber; phase 2: one mated male with one female; phase 3: two mated males with one female) were collected between 27 and 31 May 2008 from six naturally attacked wind-thrown pine trees (Pinus armandi) near Fengyu Forestry Station $\left(33^{\circ} 48^{\prime}-34^{\circ} 02^{\prime} \mathrm{N}\right.$; $108^{\circ} 42^{\prime}-$ $-108^{\circ} 52^{\prime} \mathrm{E} ; 1,600-1,900 \mathrm{~m}$ altitude), in the Qinling mountain, Shaanxi Province, China (Fig. 1). Beetles from the same gallery system were placed in a $2 \mathrm{ml}$ polyethylene centrifuge tube and immediately put into an outdoor cooler $\left(4^{\circ} \mathrm{C}\right)$. The centrifuge tubes were separated into categories according to the phase of attack in the laboratory on the day of collection and the hindguts were immediately dissected (Zhang et al., 2009a). Hindguts of females from the same attack phase and same tree were extracted using $1 \mathrm{ml}$ redistilled pentane (with $2 \mu \mathrm{g}$ of heptyl acetate as internal standard) in a $2-\mathrm{ml}$ glass vial. Hindgut extracts ( 8 to 28 guts / sample) for females from different attack phases were kept at $-20^{\circ} \mathrm{C}$ and analyzed chemically by GC-MS (gas chromatography with mass spectrometric detection) in the Analysis and Testing Center of North-West A \& F University, China.

\section{GC-MS analysis}

Chemical analyses of hindgut samples of $D$. armandi were made using a combined HP 5890 series II gas chromatograph and HP 5972 mass selective detector (GC-MSD). The GC was equipped with a $25 \mathrm{~m} \times 0.25 \mathrm{~mm}$ fused silica column, coated with CP-Wax 58 (FFAP) CB. All the samples were injected by a HP 7673 auto-injector (2 $\mathrm{ml}$ each). Helium was used as the carrier gas at a constant flow of $30 \mathrm{~cm} / \mathrm{s}$. The $\mathrm{GC}$ oven was programmed at $50^{\circ} \mathrm{C}$ for $1 \mathrm{~min}$, with a rise to $230^{\circ} \mathrm{C}$ at a rate of $10^{\circ} \mathrm{C} / \mathrm{min}$ and then kept at $230^{\circ} \mathrm{C}$ for $25 \mathrm{~min}$. Injector and transfer line temperatures were both $250^{\circ} \mathrm{C}$. Helium was used as the carrier gas at a constant flow of $30 \mathrm{~cm} / \mathrm{s}$. Volatiles were identified by comparison of the retention indices and mass spectra with those of available authentic synthetic compounds (see Chemical Standards below) using the computerized data library, NBS75K, and a custom produced library (KE1995). The relative amounts of individual compounds were calculated as

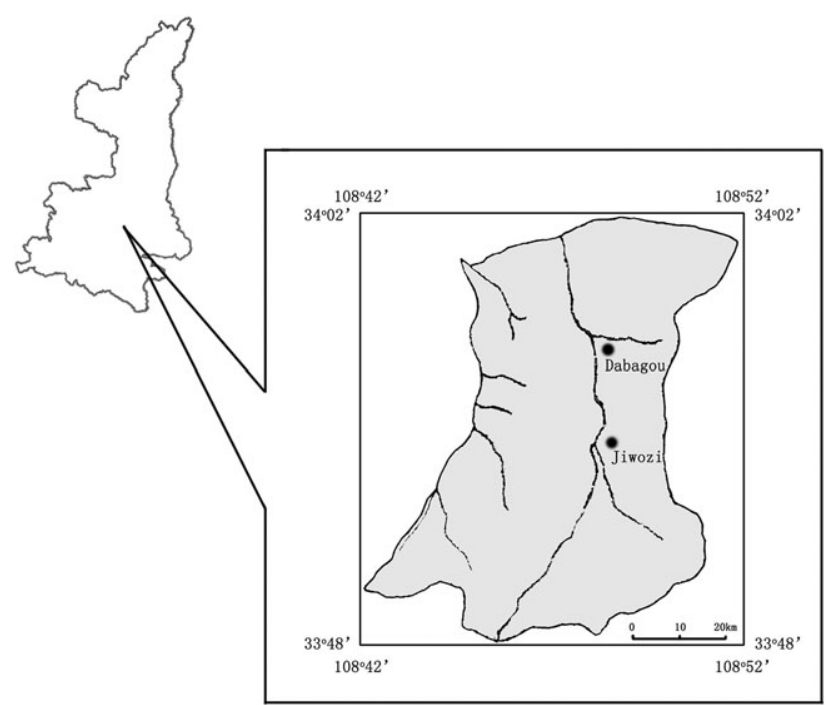

Fig. 1. Locations of the two study sites: Jiwozi and Dabagou. Left - location of Shaanxi Province in China; right - shaded area is the Fengyu Forestry Station.

percentages of whole blends. Absolute amounts were obtained by comparison with an internal standard.

\section{GC-FID analysis}

Hindgut samples were injected into a Varian CP-3800 GC equipped with a polar column $(30 \mathrm{~m} \times 0.53 \mathrm{~mm} \times 1.0 \mu \mathrm{m}$ film thickness) and FID for compound quantification based on an internal standard (IS $2 \mu \mathrm{g}$ of heptyl acetate in each sample; assuming similar or identical responses of the analytes and the IS). Helium was used as the carrier gas at a constant flow of 30 $\mathrm{cm} / \mathrm{s}$, and the injector and detector temperatures were $200^{\circ} \mathrm{C}$ and $300^{\circ} \mathrm{C}$, respectively. Column temperature was $55^{\circ} \mathrm{C}$ for $1 \mathrm{~min}$, rising to $220^{\circ} \mathrm{C}$ at $10^{\circ} \mathrm{C} / \mathrm{min}$, and then held for $10 \mathrm{~min}$ (Zhang et al., 2009).

\section{Terpene material}

$\alpha$-pinene, $(+)$-3-carene, (-)-trans-verbenol (all of 98\% chemical purity and diluted only if stated) were purchased from Fluka, AG, Switzerland and Witasek, Austria; cis-verbenol, $\beta$-caryophyllene, limonene and myrcene were obtained from SciTech, Prague, Czech Republic, Fluka, AG, Switzerland and SigmaAldrich, St. Louis, MO, USA in such and that purity. Witasek (Austria) and Zhongjie gave us (+)-3-carene and $\alpha$-pinene.

\section{Field trapping experiments}

Field trapping experiments were conducted from 15 April to 31 August 2009-2011 at Fengyu Forestry Station in the Qinling Mountains to test $D$. armandi responses to lures consisting of different combinations of semiochemicals. All experiments were conducted using multiple funnel traps (obtained from Witasek, Austria; Sino-Czech Trading Co. Ltd. Beijing, China) in a plantation with infested trees of Pinus armandii (Fig. 2). Experiments were replicated at Jiwozi and Dabagou to verify that the responses were same at different geographical locations. The Jiwozi field site was located on a north-facing slope at the Fengyu Forestry Station in the Qinling Mountains. Trees were approximately 20-30-years old and 4.5-5.0 $\mathrm{m}$ tall and were infested with $D$. armandi. As over the previous 3 years many heavily infested pine trees were felled there was very few breeding beetles and the population of $D$. armandi at Jiwozi was fairly low in 2009. In 2010, the Jiwozi field site was located in another pine tree plantation at the Fengyu Forestry Station (south-facing slope). There were mainly pine trees at the for- 

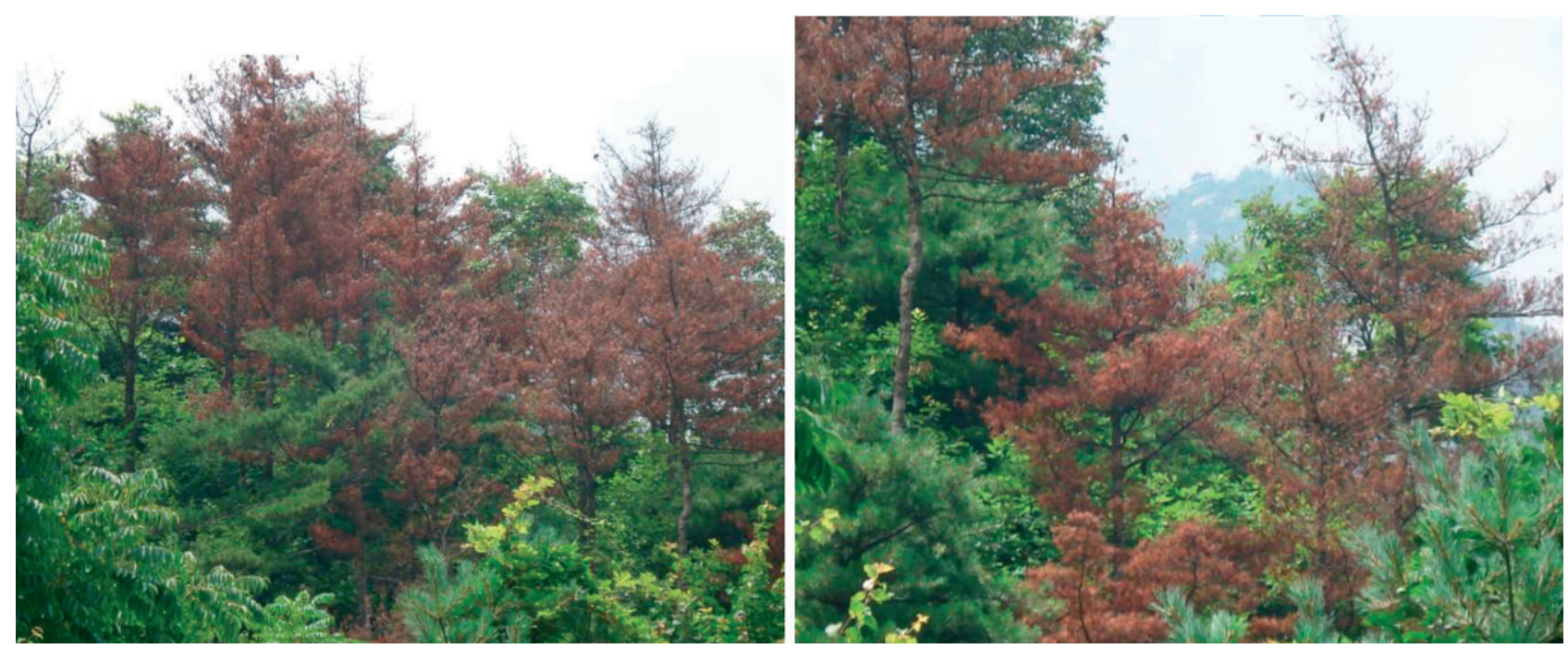

Fig. 2. Study sites of the field-trapping experiments at Fengyu Forestry Station, Shaanxi Province, China. Left - open area at Jiwozi; right - open area at Dabagou. Traps set outside the forest.

estry center, which were approximately 20-40-years old and $4.5-5.5 \mathrm{~m}$ tall and heavily infested with $D$. armandi. A single stand at Dabagou was used from 2009 to 2011. This consisted of a pine tree plantation located in the southeast of Fengyu Forestry Station, where there were high populations of $D$. armandi. Trees were approximately 20-30-years old and 4.5-5.5 m tall.

Field trapping experiment 1 was conducted from 15 April to 31 August 2009 at Jiwozi and Dabagou, Fengyu Forestry Station. It compared four treatments: (i) $\alpha$-pinene; (ii) $\alpha$-pinene, $(+)$-3-carene and (-)-trans-verbenol; (iii) cis-verbenol, $\beta$-caryophyllene, limonene and myrcene; and (iv) $\alpha$-pinene, $(+)$-3-carene, (-)-trans-verbenol, cis-verbenone, $\beta$-caryophyllene, limonene and myrcene. The $\alpha$-pinene lures were standard commercial baits (Fluka, AG), consisting of only $\alpha$-pinene released from two $15-\mathrm{mL}$ plastic vials at a combined release rate of $300 \mathrm{mg} /$ day. The blend of $\alpha$-pinene, (+)-3-carene and (-)-trans-verbenol $(2: 1: 1)$ was released from a plastic vial at $300 \mathrm{mg} /$ day. The blend of $\alpha$-pinene, limonene and $\beta$-caryophyllene $(2: 1: 1)$ was released from two $15-\mathrm{mL}$ plastic vials at a combined release rate of $300 \mathrm{mg}$ /day and myrcene released from bubble caps at a rate of $1.5 \mathrm{mg} /$ day.

Field trapping experiment 2 was conducted at Jiwozi and Dabagou from 15 April to 31 August 2010. It compared $\alpha$-pinene alone with blends of other volatiles and antennally active compounds. At Jiwozi, experiment 2 included four treatments: (i) unbaited control traps; (ii) $\alpha$-pinene; (iii) $\alpha$-pinene, (-)-trans-verbenol, (+)-3-carene and limonene; and (iv) $\alpha$-pinene, (-)-trans-verbenol, (+)-3-carene, limonene, $\beta$-caryophyllene and myrcene. The $\alpha$-pinene lures were the standard commercial baits as used in experiment 1 . The blend of $\alpha$-pinene, $(+)$-3-carene, $(-)$-trans-verbenol and limonene $(2: 1$ : $1: 1)$ was released from two plastic vials at a rate of 300 $\mathrm{mg}$ /day. The mixture of trans-verbenol and myrcene $(1: 1)$ was released from bubble caps at a rate of $1.5 \mathrm{mg} /$ day.

At Dabagou, experiment 2 included six treatments: (i) unbaited control traps; (ii) $\alpha$-pinene; (iii) $80 \% \alpha$-pinene, transverbenol, (+)-3-carene and limonene; (iv) $\alpha$-pinene, transverbenol, (+)-3-carene and limonene; (v) 75\% $\alpha$-pinene, transverbenol, (+)-3-carene and limonene; and (vi) 98\% $\alpha$-pinene, trans-verbenol, (+)-3-carene, limonene, $\beta$-caryophyllene and myrcene.

Field trapping experiment 3 was conducted from 15 April to 31 August 2011 at both Jiwozi and Dabagou. It compared the attractiveness for $D$. armandi of limonene, myrcene, and $\beta$-caryophyllene added to $\alpha$-pinene individually and in all possible combinations. In experiment 4 there were nine treatments: (i) unbaited control traps; (ii) $\alpha$-pinene; (iii) $\alpha$-pinene and limonene; (iv) $\alpha$-pinene and $\beta$-caryophyllene; (v) $\alpha$-pinene and myrcene; (vi) $\alpha$-pinene, limonene and $\beta$-caryophyllene; (vii) $\alpha$-pinene, limonene and myrcene; (viii) $\alpha$-pinene, $\beta$-caryophyllene and myrcene; (IX) $\alpha$-pinene, limonene, $\beta$-caryophyllene and myrcene. Limonene, $\beta$-caryophyllene, and myrcene were released individually from bubble caps at a rate of $10,1.5$, and $0.75 \mathrm{mg} /$ day, respectively.

All experiments were laid out in a completely randomized design with at least 20 replicates per treatment. Traps were set outside the forest, otherwise many beetles can be captured just by chance and because of the rather short flight period (few days) the position effect can be very significant even though the positions of the different traps are rotated. Treatment positions were re-randomized between collections, and the numbers of beetles captured during the different collection periods were pooled for each trap. Trapping assays were statistically evaluated using a completely randomized design.

\section{Statistics}

The data were transformed using $\log (\mathrm{xb} 1)$ to satisfy assumptions of normality. Statistical analysis was done using one-way ANOVA at a -0.05 and SPSS 16.0 for Windows, followed by LSD multiple comparison procedure to determine differences among treatments. Additionally, sex ratios of the beetles responding to the different baits were compared for homogeneity of proportions ( $\alpha=0.05$, chi-square test).

\section{RESULTS}

\section{Chemical analysis}

We identified eight major volatile compounds ( $\beta$-caryophyllene, $\alpha$-pinene, cis-verbenol, trans-verbenol, verbenone, $(+)-3$-carene, myrcene, and limonene) in the extracts of female hindguts using GC-MS and quantified them using GC-FID (Fig. 3, Table 1). Major components included $\beta$-caryophyllene, (+)-3-carene and $\alpha$-pinene, while myrcene, limonene, cis-verbenol, trans-verbenol and verbenone were minor components (Table 1). Mean amounts of the three major components $[(+)-3$-carene, 
TABLE 1. Quantities of potential semiochemicals (in nanograms) identified in extracts of the hindguts of female Dendroctonus armandi collected at different phases of their colonization of pine trees, Shaanxi Province, China, May 27-31, 2008.

\begin{tabular}{|c|c|c|c|c|c|c|c|}
\hline \multirow{3}{*}{$\begin{array}{l}\text { Retention time } \\
\qquad(\min )\end{array}$} & \multirow{3}{*}{ Chemical } & \multicolumn{6}{|c|}{ Hindguts from female beetle at different phases of the colonization } \\
\hline & & \multicolumn{2}{|c|}{$\begin{array}{c}\text { Phase } 1 \\
1+(\mathrm{N}=2 ; \mathrm{n}=15-20)\end{array}$} & \multicolumn{2}{|c|}{$\begin{array}{c}\text { Phase } 2 \\
10,1+(\mathrm{N}=2 ; \mathrm{n}=28)\end{array}$} & \multicolumn{2}{|c|}{$\begin{array}{c}\text { Phase } 3 \\
20,1 \%(\mathrm{~N}=2 ; \mathrm{n}=8-15)\end{array}$} \\
\hline & & $\mathrm{ng} /$ \& & $\%$ & $\mathrm{ng} /$ q & $\%$ & $\mathrm{ng} /$ q & $\%$ \\
\hline $5: 28$ & cis-verbenol & 109.5 & 3.3 & 89.6 & 4.0 & 80.7 & 3.7 \\
\hline $9: 57$ & $(-)$-trans-verbenol & 163.3 & 5.0 & 160.5 & 7.2 & 155.3 & 7.1 \\
\hline 30.05 & $\alpha$-pinene & 285.6 & 8.7 & 323.8 & 14.5 & 364.5 & 16.5 \\
\hline 30.50 & $\beta$-caryophyllene & 1143.6 & 34.6 & 820.3 & 36.8 & 786.5 & 35.7 \\
\hline 34.31 & $(+)$-3-carene & 1287.8 & 39.0 & 630.8 & 28.3 & 575.2 & 26.1 \\
\hline 37.50 & verbenone & 73.6 & 2.2 & 44.9 & 2.0 & 36.2 & 1.6 \\
\hline 40.51 & myrcene & 92.2 & 2.8 & 87.6 & 3.9 & 83.5 & 3.8 \\
\hline 42.28 & limonene & 145.4 & 4.4 & 73.9 & 3.3 & 121.6 & 5.5 \\
\hline
\end{tabular}

$\mathrm{N}$ - number of hindgut extracts per phase; $\mathrm{n}$ - number of hindguts per extract ( 8 to 28 hindguts/sample of females collected at different phases were analyzed chemically using GC-MS and GC-FID).

$\beta$-caryophyllene and $\alpha$-pinene] extracted from phase 1 beetles were $1287.8,1143.6$, and $285.6 \mathrm{ng} /$ female (ca. 5 : $4: 1$ ratio), respectively, which are 7-19 times greater than those of the five minor components (Table 1). Although not statistically analyzed because of too few results, the quantities of $\beta$-caryophyllene and especially $(+)$-3-carene decreased after mating (i.e., during phases 2-3), whereas those of cis-verbenol, trans-verbenol and myrcene showed no obvious changes (Table 1).

\section{Field-trapping experiment}

The responses of $D$. armandi in field-trapping experiment 1 differed between Jiwozi and Dabagou. At Daba-

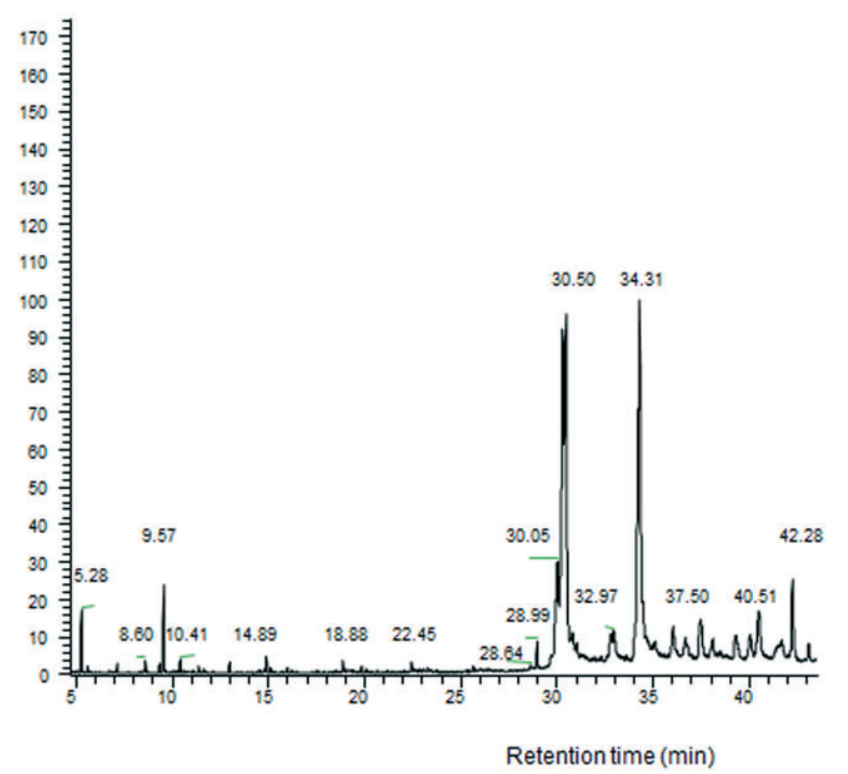

Fig. 3. Representative gas chromatogram (polar column with FID detection) of the compounds in extracts of the hindguts of female Dendroctonus armandi before mating. Heptyl acetate (HA; $2 \mu \mathrm{g} /$ sample) was added as an internal standard to the hindgut extracts. Analytes included $\beta$-carypohyllene $(\beta-c)$, cisverbenol $(\mathrm{cV}),(+)$-3-carene $(3 \mathrm{C}), \alpha$-pinene $(\alpha-p)$, trans-verbenol $(\mathrm{tV})$, verbenone (vB), limonene (Lim) and myrcene (Myr). gou, both male and female $D$. armandi were attracted in significantly higher numbers to the complete blend of $\alpha$-pinene, $(+)$-trans-verbenol, (+)-3-carene, limonene, $\beta$-caryophyllene and myrcene than to $\alpha$-pinene alone (Table 7). At Jiwozi, significantly more male and female $D$. armandi were captured in traps baited with $\alpha$-pinene alone than with any other combination of semiochemicals.

The results of field-trapping experiment 2 were very similar at Jiwozi and Dabagou. At both locations, significantly more male and female $D$. armand $i$ were captured by traps baited with the blend of $\alpha$-pinene, trans-verbenol, $(+)-3$-carene, limonene and myrcene than by traps baited with $\alpha$-pinene alone (Table 8 ). The blend that included $\alpha$-pinene, limonene, (+)-3-carene and trans-verbenol resulted in intermediate numbers of $D$. armandi being captured regardless of the enantiomeric composition of $\alpha$-pinene used at Dabagou.

In field-trapping experiment 3, at Jiwozi, significantly more $D$. armandi were captured by traps baited with the combinations $\alpha$-pinene and $\beta$-caryophyllene; $\alpha$-pinene,

TABLE 2. Tests of homogeneity of the variance in the number of males of Dendroctonus armandi captured by multiple funnel traps in field-trapping experiment $1-3$ at each site at Jiwozi and Dabagou at the Fengyu Forestry Station, Shaanxi Province, China (15 April to 31 August 2009-2011) ( $n=20$ traps per treatment).

\begin{tabular}{lccccc}
\hline & $\begin{array}{c}\text { Levene } \\
\text { statistic }\end{array}$ & df1 & df2 & Sig. \\
\hline Field-trapping exp. 1 (Jiwozi), 2009 & 2.467 & 3 & 76 & 0.09 \\
Field-trapping exp. 1 (Dabagou), 2009 & 1.146 & 3 & 76 & 0.34 \\
Field-trapping exp. 2 (Jiwozi), 2010 & 5.462 & 3 & 76 & 0.07 \\
Field-trapping exp. 2 (Dabagou), 2010 & 3.970 & 5 & 114 & 0.06 \\
Field-trapping exp. 3 (Jiwozi), 2011 & 2.184 & 8 & 171 & 0.07 \\
Field-trapping exp. 3 (Dabagou), 2011 & 1.168 & 8 & 171 & 0.08 \\
\hline
\end{tabular}

Variance in the number of males of $D$. armandi captured in experiment $1-3$ at each site are homogeneous $(\alpha=0.05)$. Data transformed using $\log (\mathrm{x}+1)$. 
TABLE 3. ANOVA of the numbers of males of Dendroctonus armandi captured by multiple funnel traps in field-trapping experiment 1-3 at Jiwozi and Dabagou at the Fengyu Forestry Station, Shaanxi Province, China (15 April to 31 August 2009-2011) (n = 20 traps per treatment).

\begin{tabular}{|c|c|c|c|c|c|c|}
\hline & Sources of variation & Sum of squares & $\mathrm{df}$ & Mean square & $\mathrm{F}$ & Sig. \\
\hline \multirow{3}{*}{$\begin{array}{l}\text { Field-trapping experiment } 1 \\
\text { (Jiwozi), } 2009\end{array}$} & Between groups & 746.204 & 3 & 248.735 & 280.347 & .000 \\
\hline & Within groups & 67.430 & 76 & 0.887 & & \\
\hline & Total & 813.634 & 79 & & & \\
\hline \multirow{3}{*}{$\begin{array}{c}\text { Field-trapping experiment } 1 \\
\text { (Dabagou), } 2009\end{array}$} & Between groups & 70959.291 & 3 & 23653.097 & 396.021 & .000 \\
\hline & Within groups & 4539.247 & 76 & 59.727 & & \\
\hline & Total & 75498.538 & 79 & & & \\
\hline \multirow{3}{*}{$\begin{array}{l}\text { Field-trapping experiment } 2 \\
\text { (Jiwozi), } 2010\end{array}$} & Between groups & 450834.596 & 3 & 150278.199 & 495.031 & .000 \\
\hline & Within groups & 23071.583 & 76 & 303.573 & & \\
\hline & Total & 473906.179 & 79 & & & \\
\hline \multirow{3}{*}{$\begin{array}{c}\text { Field-trapping experiment } 2 \\
\text { (Dabagou), } 2010\end{array}$} & Between groups & 51897.368 & 5 & 10379.474 & 1030 & .000 \\
\hline & Within groups & 1149.212 & 114 & 10.081 & & \\
\hline & Total & 53046.580 & 119 & & & \\
\hline \multirow{3}{*}{$\begin{array}{l}\text { Field-trapping experiment } 3 \\
\text { (Jiwozi), } 2011\end{array}$} & Between groups & 459033.929 & 8 & 57379.241 & 149.894 & .000 \\
\hline & Within groups & 65458.442 & 171 & 382.798 & & \\
\hline & Total & 524492.371 & 179 & & & \\
\hline \multirow{3}{*}{$\begin{array}{c}\text { Field-trapping experiment } 3 \\
\text { (Dabagou), } 2011\end{array}$} & Between groups & 41935.362 & 8 & 5241.920 & 319.630 & .000 \\
\hline & Within groups & 2804.397 & 171 & 16.400 & & \\
\hline & Total & 44739.759 & 179 & & & \\
\hline
\end{tabular}

The numbers of males trapped were significantly influenced by the treatments $(\alpha=0.05)$. Data transformed using log $(x+1)$.

$\beta$-caryophyllene and myrcene; and $\alpha$-pinene, $\beta$-caryophyllene, myrcene and limonene than by $\alpha$-pinene alone. Addition of limonene to $\alpha$-pinene did not enhance attractiveness of the bait for $D$. armandi and the responses to the other combinations were intermediate between those to $\alpha$-pinene alone and $\alpha$-pinene plus $\beta$-caryophyllene (Table 9). At Dabagou, all of the treatment combinations resulted in significantly higher numbers of $D$. armandi captured than by $\alpha$-pinene alone (Table 9).

In field-trapping experiment 2 , only the blend that included $\beta$-caryophyllene and myrcene resulted in significantly higher trap catches $(217-243 \%$ higher $)$ than $\alpha$-pinene alone (Table 8). Similarly, in field-trapping experiment 3 at Jiwozi, $\alpha$-pinene in combination with $\beta$-caryophyllene or with myrcene or myrcene and limonene significantly enhanced the attractiveness of the bait for $D$. armandi by $175 \%, 161 \%$ and $172 \%$, respectively (Table 9). At Dabagou, the addition of $\beta$-caryophyllene, myrcene and limonene, individually, or in any combination, significantly increased the attractiveness of the bait for $D$. armandi by up to $243 \%$ compared to $\alpha$-pinene alone (Table 9). At both Jiwozi and Dabagou, traps with baits that contained $\beta$-caryophyllene captured significantly more $D$. armandi than those that did not (Tables 7-9). Results for field-trapping experiment 1 at Jiwozi and Dabagou, in which $\beta$-caryophyllene was not included in any of the baits, were inconsistent and the overall number of beetles captured at Jiwozi was very low. Because many heavily infested pine trees were cut down during the previous 3 years there was very little breeding material available and the population of $D$. armandi at Dabagou was fairly low in 2009.

\section{DISCUSSION AND CONCLUSIONS}

This is the first chemical and behavioural analysis of the semiochemicals of $D$. armandi in the Qinling Mountains. Results of GC-MS and GC-FID analysis of the $D$. armandi semiochemicals demonstrate that the major com-

TABLE 4. $\chi^{2}$ analysis of the ratio of males to females in the catches of all the traps used in the three experiments at Jiwozi and Dabagou.

\begin{tabular}{|c|c|c|c|c|c|c|}
\hline & \multicolumn{2}{|c|}{ Field-trapping experiment 1} & \multicolumn{2}{|c|}{ Field-trapping experiment 2} & \multicolumn{2}{|c|}{ Field-trapping experiment 3} \\
\hline & (Jiwozi) & (Dabagou) & (Jiwozi) & (Dabagou) & (Jiwozi) & (Dabagou) \\
\hline & 2009 & 2009 & 2010 & 2010 & 2011 & 2011 \\
\hline Chi-Square & 10.908 & 12.721 & 178.3 & 26.262 & 28.634 & 14.948 \\
\hline df & 1 & 1 & 1 & 1 & 1 & 1 \\
\hline Asymp. sig. & .024 & .03 & .000 & .000 & .000 & .000 \\
\hline
\end{tabular}

The ratios of males to females caught by all the traps used in each experiment at both sites are significantly different $(\alpha=0.05)$. 
TABLE 5. Tests of homogeneity of variance of the numbers of males of Dendroctonus armandi captured in field-trapping experiment 1-3 (15 April to 31 August 2009-2011) ( $\mathrm{n}=20$ traps per treatment).

\begin{tabular}{lcccc}
\hline Sites & Levene statistic & df1 & df2 & Sig. \\
\hline Field-trapping experiment 1, 2009 & 1.615 & 1 & 158 & .206 \\
Field-trapping experiment 2, 2010 & 3.945 & 1 & 198 & 0.072 \\
Field-trapping experiment 3, 2011 & 2.135 & 1 & 358 & .145 \\
\hline
\end{tabular}

Variance in the numbers of males of $D$. armandi captured in experiment $1-3$ is homogeneous $(\alpha=0.05)$. Data transformed by log (x $+1)$.

ponents in the extracts of female hindguts were $\alpha$-pinene, $\beta$-caryophyllene and (+)-3-carene, with myrcene, limonene, verbenol and verbenone minor components (Fig. 3, Table 1). Although the results were not statistical analyzed because of the small amount data, the quantities of $\beta$-caryophyllene and especially $(+)-3$-carene decreased after mating (i.e., during phases 2-3), whereas those of cis- verbenol trans-verbenol and myrcene did not change (Table 1). GC-FID analyses indicated a large variation in the quantities of volatiles in the extracts of female hindguts at different phases of the attack. The maximum amounts of the major components occurred in phases 1-2, when the nuptial chamber was finished, or only one male was present. The results of our experiments, together with other research demonstrating that $\beta$-caryophyllene occurs in the digestive tract of $D$. armandi, support the designation of $\beta$-caryophyllene as one of the semiochemicals of $D$. armandi. Other compounds frequently found in many other bark beetles, but not confirmed as semiochemicals, such as myrtenol and myrcene, were also detected as minor components (Bakke et al., 1977; Birgersson et al., 1984; Schlyter et al., 1987; Zhang et al., 2000a, b). However, we identified and quantified 3 groups of hindgut volatiles ( $\beta$-caryophyllene; the pinene alcohols including trans-verbenol, cis-verbenol, limonene and myrcene; $(+)-3$-carene and $\alpha$-pinene) in the extracts of female hindguts (Fig. 3, Table 1).

Semiochemicals are an attractive option for managing bark beetles, because of their perceived lack of environmental intrusiveness, flexibility and simplicity of application compared to other traditional options. Research on the use of disruptant or attractant semiochemicals for protecting trees from attack by species of Dendroctonus has been ongoing since the discovery of scolytid disruptant semiochemicals in America (Wilson et al., 1996). During the past few decades, there has been great progress in the study of the semiochemicals used by bark beetles. However, when used for direct control or resource protection, disruptant or attractant semiochemicals have been plagued by inconsistent results (Wood, 1982; Bertram et al., 1994a, b). The natural biological and ecological effects of semiochemicals are complex or unknown, making their successful application difficult. Recent investigations identified previously unknown semiochemicals for several species of bark beetles (Pureswaran $\&$ Borden, 2004; Sullivan, 2005). Some of these semiochemicals are potential inhibitors of bark beetle attraction (Dickens et al., 1992; Pureswaran \& Borden, 2004). It is likely that our poor knowledge of how semiochemicals interact with the environment, behavioural complexities and performance of release devices are in part responsible for the poor effectiveness of the traps. Improving the methods used to evaluate and predict semiochemical effects, along with determining the environmental factors that affect when and where semiochemicals can be efficiently and effectively deployed, are keys to their future utility as tools for bark beetle management.

In recent years, $D$. armandi infestations appear to be increasing throughout the Northwest of China. D. armandi mostly lives in the high and steep mountainous areas in the Qinling Mountains, so it is often difficult to use traditional methods for controlling this beetle. Semiochemical traps are very effective as they catch insects even when present at very low densities. They are often used to detect the presence of exotic pests, or for sampling, monitoring or determining the first appearance of a

TABLE 6. ANOVA of the numbers of males of Dendroctonus armandi captured in field-trapping experiment 1-3 at each location (15 April to 31 August 2009-2011) ( $\mathrm{n}=20$ traps per treatment).

\begin{tabular}{|c|c|c|c|c|c|c|}
\hline & Sources of variation & Sum of squares & $\mathrm{df}$ & Mean square & $\mathrm{F}$ & Sig. \\
\hline \multirow{3}{*}{$\begin{array}{l}\text { Field-trapping experiment } 1 \\
\text { (Jiwozi), } 2009\end{array}$} & Between groups & 40.912 & 1 & 40.912 & 1524 & .000 \\
\hline & Within groups & 4.240 & 158 & .027 & & \\
\hline & Total & 45.152 & 159 & & & \\
\hline \multirow{3}{*}{$\begin{array}{l}\text { Field-trapping experiment } 1 \\
\text { (Dabagou), } 2009\end{array}$} & Between groups & 5.443 & 1 & 5.443 & 26.637 & .000 \\
\hline & Within groups & 40.459 & 198 & .204 & & \\
\hline & Total & 45.902 & 199 & & & \\
\hline \multirow{3}{*}{$\begin{array}{l}\text { Field-trapping experiment } 2 \\
\text { (Jiwozi), } 2010\end{array}$} & Between groups & 20.897 & 1 & 20.897 & 117.908 & .000 \\
\hline & Within groups & 63.448 & 358 & .177 & & \\
\hline & Total & 84.344 & 359 & & & \\
\hline
\end{tabular}

The numbers of males trapped were significantly influenced by the treatments $(\alpha=0.05)$. Data transformed using $\log (\mathrm{x}+1)$. 
TABLE 7. Mean $( \pm \mathrm{SEM})$ number of Dendroctonus armandi captured by multiple funnel traps in field-trapping experiment 1 at Jiwozi and Dabagou at the Fengyu Forestry Station, Shaanxi Province, China (15 April to 31 August 2009) ( $\mathrm{n}=20$ traps per treatment).

\begin{tabular}{|c|c|c|c|}
\hline \multirow{2}{*}{ Treatment } & \multirow{2}{*}{ Number of traps } & \multicolumn{2}{|c|}{ Mean number of Dendroctonus armandi captured/trap } \\
\hline & & Males & Females \\
\hline \multicolumn{4}{|l|}{ Jiwozi } \\
\hline$\alpha-p$ & 20 & $13.2 \pm 1.5^{\mathrm{a}}$ & $12.6 \pm 1.6^{\mathrm{a}}$ \\
\hline$\alpha-p+3 C+t V$ & 20 & $4.5 \pm 0.5^{\mathrm{c}}$ & $4.3 \pm 0.5^{\mathrm{c}}$ \\
\hline $\mathrm{cV}+\beta-\mathrm{c}+\mathrm{Lim}+\mathrm{Myr}$ & 20 & $7.1 \pm 0.6^{b}$ & $7.0 \pm 0.6^{b}$ \\
\hline$\alpha-p+3 C+t V+c V+\beta-c+\operatorname{Lim}+\mathrm{Myr}$ & 20 & $7.3 \pm 0.8^{\mathrm{b}}$ & $5.6 \pm 0.5^{\mathrm{b}, \mathrm{c}}$ \\
\hline \multicolumn{4}{|l|}{ Dabagou } \\
\hline$\alpha-p$ & 20 & $45.3 \pm 5.8^{\mathrm{b}, \mathrm{c}}$ & $50.3 \pm 5.9^{\mathrm{b}, \mathrm{c}}$ \\
\hline$\alpha-p+3 C+t V$ & 20 & $82.5 \pm 6.4^{\mathrm{c}}$ & $85.4 \pm 6.8^{\mathrm{c}}$ \\
\hline $\mathrm{cV}+\beta-\mathrm{c}+\mathrm{Lim}+\mathrm{Myr}$ & 20 & $108.3 \pm 8.4^{\mathrm{a}, \mathrm{b}}$ & $102.2 \pm 6.7^{\mathrm{b}}$ \\
\hline$\alpha-p+3 C+t V+c V+\beta-c+\operatorname{Lim}+M y r$ & 20 & $122.6 \pm 13.3^{\mathrm{a}}$ & $129.3 \pm 19.5^{\mathrm{a}}$ \\
\hline
\end{tabular}

Means within a column, for each site, followed by the same superscript letter are not significantly different, LSD test on data transformed using $\log (\mathrm{x}+1), P \leq 0.05$. The total number of Dendroctonus armandi captured in each trap was counted. Baits consisted of $\alpha$-pinene released at $300 \mathrm{mg} / \mathrm{day}(\mathrm{Ie}) ; \alpha$-pinene: $(+)-3$-carene: trans-verbenol $(2: 1: 1)$ released as a mixture at $300 \mathrm{mg} / \mathrm{day}(\alpha-\mathrm{p}+$ $3 \mathrm{C}+\mathrm{tV})$; and a two-part lure consisting of $\alpha$-pinene, $\beta$-caryophyllene and limonene $(2: 1: 1)$ released as a mixture at $300 \mathrm{mg} / \mathrm{day}$ and myrcene released at $0.75 \mathrm{mg} /$ day from a separate device $(\mathrm{cV}+\beta-\mathrm{c}+\mathrm{Lim}+\mathrm{Myr})$.

pest in an area. The fact that semiochemical traps are highly species-specific can also be an advantage, and they tend to be inexpensive and easy to implement.

Some of the difficulties we experienced in using semiochemical traps in the field were their sensitivity to bad weather, ability to attract bark beetles from neighbouring areas and they only attract adults of $D$. armandi. We only report the release rates of the entire blend, however, it may be more appropriate to report the release rates of each compound in each blend, since compounds elute at different rates and when in combination can interact with each other altering the elution rates. Our study is the first step in a series of field bioassays of the attractiveness of candidate semiochemicals for $D$. armandi. Before the effectiveness and utility of a potential treatment can be determined, further experiments need to be done.

These beetles either attack non-colonized areas of the main stem on newly-infested trees or initiate colonization

TABLE 8. Mean ( \pm SEM) number of Dendroctonus armandi captured by multiple funnel traps in field-trapping experiment 2 at Jiwozi and Dabagou at the Fengyu Forestry Station, Shaanxi Province, China (15 April to 31 August 2010) ( $\mathrm{n}=20$ traps per treatment).

\begin{tabular}{|c|c|c|c|}
\hline \multirow{2}{*}{ Treatment } & \multirow{2}{*}{ Number of traps } & \multicolumn{2}{|c|}{ Mean number of Dendroctonus armandi captured/trap } \\
\hline & & Males & Females \\
\hline \multicolumn{4}{|l|}{ Jiwozi } \\
\hline Unbaited control & 20 & $7.2 \pm 1.8^{\mathrm{c}}$ & $3.4 \pm 0.5^{\mathrm{c}}$ \\
\hline$\alpha-p$ & 20 & $109.5 \pm 11.3^{\mathrm{b}}$ & $118.6 \pm 13.1^{\mathrm{b}}$ \\
\hline$\alpha-p+3 C+t V+\operatorname{Lim}$ & 20 & $122.7 \pm 15.8^{\mathrm{b}}$ & $149.2 \pm 28.5^{\mathrm{a}, \mathrm{b}}$ \\
\hline$\alpha-p+3 C+t V+\operatorname{Lim}+\beta-c+M y r$ & 20 & $213.3 \pm 38.7^{\mathrm{a}}$ & $282.6 \pm 51.5^{\mathrm{a}}$ \\
\hline \multicolumn{4}{|l|}{ Dabagou } \\
\hline Unbaited control & 20 & $4.3 \pm 1.9^{\mathrm{c}}$ & $3.3 \pm 0.8^{\mathrm{c}}$ \\
\hline$\alpha-p$ & 20 & $31.5 \pm 3.2^{\mathrm{b}}$ & $28.3 \pm 2.9^{\mathrm{b}}$ \\
\hline$(80 \%-) \alpha-p+3 C+t V+\operatorname{Lim}$ & 20 & $38.3 \pm 3.6^{\mathrm{a}, \mathrm{b}}$ & $35.4 \pm 3.3^{\mathrm{a}, \mathrm{b}}$ \\
\hline$(+/-) \alpha-p+3 C+t V+\operatorname{Lim}$ & 20 & $44.8 \pm 4.3^{\mathrm{a}, \mathrm{b}}$ & $41.4 \pm 4.8^{\mathrm{b}}$ \\
\hline$(75 \%+) \alpha-p+3 C+t V+\operatorname{Lim}$ & 20 & $40.4 \pm 3.8^{\mathrm{a}, \mathrm{b}}$ & $36.3 \pm 3.5^{\mathrm{a}, \mathrm{b}}$ \\
\hline$\alpha-p+3 C+t V+\operatorname{Lim}+\beta-c+M y r$ & 20 & $75.7 \pm 5.3^{\mathrm{a}}$ & $69.5 \pm 5.1^{\mathrm{a}}$ \\
\hline
\end{tabular}

Means within a column followed by the same superscript letter are not significantly different, LSD test on data transformed using $\log (\mathrm{x}+1), P \leq 0.05$. The total number of Dendroctonus armandi captured in each trap was counted. Baits consisted of $\alpha$-pinene $(98 \%-)$ released at $300 \mathrm{mg} /$ day; $\alpha$-pinene $(80 \%-, 75 \%+$, or $+/-):(+)-3$-carene: trans-verbenol: limonene $(2: 1: 1: 1)$ released as a mixture at $300 \mathrm{mg} / \mathrm{day}(\alpha-\mathrm{p}+3 \mathrm{C}+\mathrm{tV}+\mathrm{Lim})$; and a two-part lure consisting of $\alpha$-pinene $(80 \%-)$ : (+)-3-carene: trans-verbenol: limonene $(2: 1: 1: 1)$ released as a mixture at $300 \mathrm{mg} /$ day and $\beta$-caryophyllene: myrcene $(1: 1)$ released from a separate device at $1.5 \mathrm{mg} /$ day $(\alpha-\mathrm{p}+3 \mathrm{C}+\mathrm{tV}+\mathrm{Lim}+\beta-\mathrm{c}+\mathrm{Myr})$. 
TABLE 9. Mean $( \pm \mathrm{SEM})$ number of Dendroctonus armandi captured by multiple funnel traps in field-trapping experiment 3 at Jiwozi and Dabagou at the Fengyu Forestry Station, Shaanxi Province, China (15 April to 31 August 2011) ( $\mathrm{n}=20$ traps per treatment).

\begin{tabular}{|c|c|c|c|}
\hline \multirow{2}{*}{ Treatment } & \multirow{2}{*}{ Number of traps } & \multicolumn{2}{|c|}{ Mean number of Dendroctonus armandi captured/trap } \\
\hline & & Males & Females \\
\hline \multicolumn{4}{|l|}{ Jiwozi } \\
\hline Unbaited control & 20 & $4.3 \pm 1.9^{c}$ & $3.2 \pm 0.6^{\mathrm{c}}$ \\
\hline$\alpha-p$ & 20 & $108.7 \pm 11.3^{\mathrm{b}, \mathrm{c}}$ & $93.5 \pm 10.6^{\mathrm{b}}$ \\
\hline$\alpha-p+\operatorname{Lim}$ & 20 & $93.3 \pm 12.3^{\mathrm{c}}$ & $105.6 \pm 12.1^{\mathrm{b}}$ \\
\hline$\alpha-p+\beta-c$ & 20 & $177.2 \pm 28.5^{\mathrm{a}}$ & $175.7 \pm 26.3^{\mathrm{a}}$ \\
\hline$\alpha-p+M y r$ & 20 & $141.4 \pm 16.5^{\mathrm{b}, \mathrm{c}}$ & $101.3 \pm 12.4^{\mathrm{b}}$ \\
\hline$\alpha-p+\operatorname{Lim}+\beta-c$ & 20 & $164.3 \pm 27.1^{\mathrm{a}, \mathrm{b}}$ & $160.5 \pm 32.3^{\mathrm{a}, \mathrm{b}}$ \\
\hline$\alpha-p+\operatorname{Lim}+\operatorname{Myr}$ & 20 & $141.5 \pm 16.2^{\mathrm{a}, \mathrm{b}, \mathrm{c}}$ & $136.6 \pm 18.5^{\mathrm{a}, \mathrm{b}}$ \\
\hline$\alpha-p+\beta-c+M y r$ & 20 & $166.2 \pm 27.3^{\mathrm{a}, \mathrm{b}}$ & $162.5 \pm 31.6^{\mathrm{a}, \mathrm{b}}$ \\
\hline$\alpha-p+\operatorname{Lim}+\beta-c+\operatorname{Myr}$ & 20 & $170.3 \pm 15.8^{\mathrm{a}, \mathrm{b}}$ & $177.1 \pm 19.3^{\mathrm{a}, \mathrm{b}}$ \\
\hline \multicolumn{4}{|l|}{ Dabagou } \\
\hline Unbaited control & 20 & $2.4 \pm 1.5^{\mathrm{c}}$ & $1.8 \pm 0.4^{\mathrm{c}}$ \\
\hline$\alpha-p$ & 20 & $26.5 \pm 3.3^{\mathrm{b}}$ & $25.3 \pm 3.2^{\mathrm{b}}$ \\
\hline$\alpha-p+\operatorname{Lim}$ & 20 & $36.2 \pm 4.5^{\mathrm{a}, \mathrm{b}}$ & $34.6 \pm 4.1^{\mathrm{a}}$ \\
\hline$\alpha-p+\beta-c$ & 20 & $43.5 \pm 4.7^{\mathrm{a}, \mathrm{b}}$ & $47.2 \pm 5.2^{\mathrm{a}}$ \\
\hline$\alpha-p+M y r$ & 20 & $41.2 \pm 4.3^{\mathrm{a}, \mathrm{b}}$ & $43.1 \pm 3.1^{\mathrm{a}}$ \\
\hline$\alpha-p+\operatorname{Lim}+\beta-c$ & 20 & $46.2 \pm 5.1^{\mathrm{a}, \mathrm{b}}$ & $52.5 \pm 5.3^{\mathrm{a}}$ \\
\hline$\alpha-p+\operatorname{Lim}+\operatorname{Myr}$ & 20 & $44.5 \pm 3.8^{\mathrm{a}, \mathrm{b}}$ & $47.5 \pm 4.4^{\mathrm{a}}$ \\
\hline$\alpha-p+\beta-c+M y r$ & 20 & $52.2 \pm 4.8^{\mathrm{a}}$ & $55.7 \pm 4.9^{\mathrm{a}}$ \\
\hline$\alpha-p+\operatorname{Lim}+\beta-c+M y r$ & 20 & $58.6 \pm 5.3^{\mathrm{a},}$ & $67.2 \pm 6.2^{\mathrm{a}}$ \\
\hline
\end{tabular}

Means within a column followed by the same superscript letter are not significantly different, LSD test on data transformed using $\log (\mathrm{x}+1), P \leq 0.05$. The total number of Dendroctonus armandi captured in each trap was counted. Baits consisted of $\alpha$-pinene $(\alpha-p)$ released at $300 \mathrm{mg} /$ day, limonene $(\mathrm{Lim})$ released at $15 \mathrm{mg} /$ day, $\beta$-caryophyllene $(\beta-\mathrm{c})$ released at $1.5 \mathrm{mg} / \mathrm{day}$, and myrcene (Myr) released at $0.75 \mathrm{mg} /$ day.

of adjacent, uninfested trees. Many of the compounds that we identified in the extracts of the hindguts of female $D$. armandi are tree phytochemicals and microbial byproducts. However, further tests are planned to solve these problems and ensure that we collect only beetle volatiles and not tree and microbial volatiles. Volatiles isolated from the hindguts of females are semiochemicals. The work to prove these are sex pheromones will require another study.

In general, our results indicate that the addition of $\beta$-caryophyllene to either $\alpha$-pinene alone or to blends of $\alpha$-pinene and other candidate semiochemicals significantly enhanced their attractiveness for $D$. armandi. At both Jiwozi and Dabagou, traps that contained $\beta$-caryophyllene consistently captured more $D$. armandi than traps that did not. Also, traps that are baited with a combination of $\alpha$-pinene and $\beta$-caryophyllene are simple to use, relatively inexpensive to manufacture and produce consistent results. Therefore, a simple lure consisting of $\alpha$-pinene and $\beta$-caryophyllene would be the optimal one for trapping $D$. armandi in the Qinling Mountains of the People's Republic of China.

ACKNOWLEDGEMENTS. We thank A. Schopf (BOKU University, Austria) who trained us in the technical aspects of this study and X. Gou for reviewing an earlier version of this manuscript. This study was supported by a 948 project from State
Forestry Bureau of China (11-4-66), NSFC(31070582), "PCSIRT" (IRT1035) and special funding from NWSUAF (QN2009057).

\section{REFERENCES}

Bakke A., Frayen P. \& Skattebal L. 1977: Field response to a new pheromone compound isolated from Ips typographus. Naturwissenschaften 64: 98-99.

Bertram S.L. \& PaINE T.D. 1994a: Influence of aggregation inhibitors (verbenone and ipsdienol) on landing and attack behavior of Dendroctonus brevicomis (Coleoptera: Scolytidae). J. Chem. Ecol. 20: 1617-1629.

Bertram S.L. \& Paine T.D. 1994b: Response of Dendroctonus brevicomis LeConte (Coleoptera: Scolytidae) to different release rates and ratios of aggregation semiochemicals and the inhibitors verbenone and ipsdienol. J. Chem. Ecol. 20: $1617-1629$.

Birgersson G., Schlyter F., Lofqvist J. \& Bergstrom G. 1984: Quantitative variation of pheromone components in the spruce bark beetle Ips typographus from different attack phases. J. Chem. Ecol. 10: 1029-1055.

BLAZENEC M. \& JAKUS R. 2009: Effect of $(+)$-limonene and 1-methoxy-2-propanol on Ips typographus response to pheromone blends. J. For. Res. 20: 37-44.

BYERS J.A. 1999: Effects of attraction radius and flight paths on catch of scolytid beetles dispersing outward through rings of pheromone traps. J. Chem. Ecol. 25: 985-1005. 
Chen H., Tang M., Gao J.M., Chen X. \& Li Z.B. 2006: Changes in the compositions of volatile monoterpenes and sesquiterpenes of Pinus armandi, P. tabulaeformis and P. bungeana in northwest China. Chem. Nat. Comp. 42: 430-433.

Dickens J.C., Billings R.F. \& Payne T.L. 1992: Green leaf volatiles interrupt aggregation pheromone response in bark beetles infecting pines. Experientia 48: 523-524.

Erbilgin N., Mori S.R., Sun J.H., Stein J.D., Owen D.R., Merrill L.D., Campos B.R., Raffa K.F., Mendez M.T., Wood D.L. \& Gillette N.E. 2007: Quantitative variation and biosynthesis of hindgut volatiles associated with the red turpentine beetle, Dendroctonus valens LeConte, at different attack phases. J. Chem. Ecol. 33: 131-146.

Faccoli M. \& Stergluc F. 2008: Damage reduction and performance of mass trapping devices for forest protection against the spruce bark beetle. Ann. For. Sci. 65: 309.

Fettig C.J., Dabney C.P., McKelvey S.R. \& Huber D.P. 2008 Nonhost angiosperm volatiles and verbenone protect individual ponderosa pines from attack by western pine beetle and red turpentine beetle (Coleoptera: Curculionidae, Scolytinae). West. J. Appl. For. 23: 40-45.

Huber D.P., Gries R., Borden J.H. \& Pierce H.D. 1999: Two pheromones of coniferophagous bark beetles (Coleoptera: Scolytidae) found in the bark of nonhost angiosperms. $J$. Chem. Ecol. 25: 805-816.

Hughes P.R. 1973: Quantitative variation and biosynthesis of hindgut volatiles associated with the red turpentine beetle, Dendroctonus valens LeConte, at different attack phases. $Z$. Angew. Entomol. 73: 294-312.

Li J.S., Chang G.B., Song Y.S., Wang Y.W. \& Chang B.S. 2001: Control project on red turpentine beetle (Dendroctonus valens). Forest Pest Dis. 4: 41-44.

Miao Z.W., Chou W.M., Huo F.Y., Wang X.L., Fang J.X \& Zhао M.M. 2001: Biology of Dendroctonus valens in Shanxi Province. Shanxi For. Sci. Tech. 23: 34-37.

Pureswaran D.S. \& Borden J.H. 2004: New repellent semiochemicals for three species of Dendroctonus (Coleoptera: Scolytidae). Chemoecology 14: 67-75.

Pureswaran D.S., Hofstetter R.W. \& Sulivan B.T. 2008: Attraction of the southern pine beetle, Dendroctonus frontalis, to pheromone components of the western pine beetle, Dendroctonus brevicomis (Coleoptera: Curculionidae: Scolytinae), in an allopatric zone. Environ. Entomol. 37: 70-78.

SChlyter F., Birgersson G. \& LafQvist J. 1987: Behavioral sequence in the attraction of the bark beetle Pheromone and terpene attraction in the bark beetle Ips typographus to pheromone sources. Physiol. Entomol. 12: 185-196.

STEPHEN C. 2001: Review of the operational IPM program for the southern pine beetle. Integr. Pest Manag. Rev. 6: 293-301.
Sullivan B.T. 2005: Electrophysiological and behavioral responses of Dendroctonus frontalis (Coleoptera: Curculionidae) to volatiles isolated from conspecifics. J. Econ. Entomol. 98: 2067-2078.

Wilson I.M., Borden J.H., Gries R. \& Gries G. 1996: Green leaf volatiles as antiaggregants for the mountain pine beetle, Dendroctonus ponderosae Hopkins (Coleoptera: Scolytidae). J. Chem. Ecol. 22: 1861-1875.

Wood D. 1982: The role of pheromones, kairmones, and allomones in the host selection and colonization behavior of bark beetles. Annu. Rev. Entomol. 27: 411-446.

YIN H.F. 2000: A synopsis of morphological and biological characters of Dendroctonus valens LeConte. Acta Zootaxon. Sin. 251: 120.

ZHANG L.W. \& SUN J.H. 2006: Quantitative variation and biosynthesis of hindgut volatiles associated with the red turpentine beetle, Dendroctonus valens LeConte, at different attack phases. Environ. Entomol. 35: 1232-1237.

Zhang Q.H., Birgersson G., Zhu J.W., Lofstedt C., LofQvist J. \& SCHLYTER F. 1999a: Leaf volatiles from nonhost deciduous trees: variation by tree species, season, and temperature and electrophysiological activity in Ips typographus. J. Chem. Ecol. 25: 1923-1943.

Zhang Q.H., Schlyter F. \& Anderson P. 1999b: Green leaf volatiles interrupt pheromone response of spruce bark beetle, Ips typographus. J. Chem. Ecol. 25: 2847-2861.

Zhang Q.H., Birgersson G., Schlyter F. \& Chen G.F. 2000a: Quantitative variation and biosynthesis of hindgut volatiles associated with the red turpentine beetle, Dendroctonus valens LeConte, at different attack phases. J. Chem. Ecol. 26: 841-858.

Zhang Q.H., Schlyter F. \& Birgersson G. 2000b: Bark volatiles from nonhost angiosperm trees of spruce bark beetle, Ips typographus (L.) (Coleoptera: Scolytidae): Chemical and electrophysiological analysis. Chemoecology 10: 69-80.

Zhang Q.H., Erbilgin N. \& Seybold S.J. 2008: Quantitative variation and biosynthesis of hindgut volatiles associated with the red turpentine beetle, Dendroctonus valens LeConte, at different attack phases. Chemoecology 18: 243-254.

Zhang L.W., Clarke S.R. \& Sun J.H. 2009a: Electrophysiological and behavioral responses of Dendroctonus valens (Coleoptera: Curculionidae: Scolytinae) to four bark beetle pheromones. Environ. Entomol. 38: 472-477.

Zhang Q.H. \& Ma J.H. \& Zhao F.Y. \& Song L.W. \& Sun J.H. 2009b: Aggregation pheromone of the Qinghai spruce bark beetle, Ips nitidus Eggers. J. Chem. Ecol. 35: 610-617.

Received October 30, 2011; revised and accepted June 6, 2012 